www.jmscr.igmpublication.org

Impact Factor 3.79

Index Copernicus Value: 5.88

ISSN (e)-2347-176x ISSN (p) 2455-0450

crossref DOI: _http://dx.doi.org/10.18535/jmscr/v3i12.15

Journal Of Medical Science And Clinical Research

\title{
Complications of Hemodialysis
}

\author{
Authors \\ Dr Kavita Krishna ${ }^{1}$, Dr Nitin Gadkari , Dr Gagan Jain ${ }^{3}$, Dr Arundhati Diwan ${ }^{4}$, \\ Dr Vivek Nikam5 ${ }^{5}$ Dr Snehal Rahane ${ }^{6}$, Dr Apoorva Saoji ${ }^{7}$ \\ ${ }^{1}$ Professor, Department of General Medicine, Bharati Medical College, Pune \\ ${ }^{2}$ Associate Professor, Department of General Medicine, Bharati Medical College, Pune \\ ${ }^{3}$ Postgraduate, Department of General Medicine, Bharati Hospital, Pune \\ ${ }^{4}$ Professor and Head, Department of General Medicine, Bharati Hospital, Pune \\ ${ }^{5}$ PostGraduate, Department of General Medicine, Bharati Hospital, Pune \\ ${ }^{6}$ Postgraduate, Department of General Medicine, Bharati Hospital, Pune \\ ${ }^{7}$ Undergraduate, Department of General Medicine, Bharati Hospital, Pune \\ Corresponding Author \\ Dr Kavita Krishna \\ Dept of General Medicine, Bharati Hospital and Research Centre, Dhankawadi, Pune \\ Maharashtra - 411043 India, \\ Email: kavitakrishna2006@gmail.comPh.No.8975554160
}

\begin{abstract}
This study is conducted to determine the frequency of complications related to Hemodialysis (HD) in case of Acute kidney injury(AKI) and Chronic kidney disease (CKD) and to compare the prevalence of different complications. To correlate the prevalence of various complications in Chronic Kidney Disease on maintenance Hemodialysis with relation to duration of CKD as well as associated comorbidities. Three thousand consecutive Hemodialysis performed at the Dialysis Unit were screened. The indications for the $H D$ were noted. These were patients of AKI, CKD and poisoning of these who developed complications during or immediately after HD were taken up for the study. Out of the total number of patients undergoing HD, 87.8\% had CKD and 12.1\% had (AKI).Out of 3000 episode of HD, 99 (3.33\%) had complications. Since few episodes had more than one complication, total complications were 168. Age group of 61-70 years had the maximum number of complications (30.3\%).CKD patients had more number of complications than Acute kidney injury (AKI) and the most frequent complication occurring during HD was vascular access (18.18\%) and hypotension(18.18\%) and the least was hypertension(1.01\%). Patients having both DM and HTN as comorbidities had more severe and fatal complications than patients having just any one co morbidity with maximum number of complications occurring in age group of 61-70 years.
\end{abstract}

\section{INTRODUCTION}

In today's era the global burden of patients needing Hemodialysis (HD) for various indications is increasing. But even with advancement and refinement of dialysis techniques a large number of complications are associated with this procedure. There is a need to minimize these complications so as to decrease the mortality and morbidity. The present study was undertaken keeping this aim, so that based on 
its results some guidelines maybe formulated to prevent and effectively deal with these complications.

\section{MATERIAL AND METHODS}

3000episodes of HD performed were screened at the Dialysis Unit in patients of AKI, poisoning and CKD above age of 18 .Of these patients, who developed complications during or immediately after HD were taken up for the study. Details of the HD-vascular access, HD dialyzate and procedure machine were noted. Patient details regarding clinical history, diagnosis, reasons for HD, duration and frequency of HD were noted. Detailed clinical examination was done pre and post HD. Symptoms of complications during and immediately after HD was noted. Relevant investigations hematological and biochemical as needed were done and the outcome was monitored. Vascular access was either femoral or subclavian or internal jugular vein.

\section{OBSERVATIONS AND RESULTS}

The study consisted of 3000 episodes of HD, undertaken to study complications of dialysis, which occurred during/post dialysis over a period of two years from June 2011 to May 2013. Out of 3000 episode of HD, $99 \quad(3.33 \%)$ had complications. Since few episodes had more than one complication, total complications were 168.[Table1] Out of total 99 episodes of HD having complications, 69 were seen in males $(69.69 \%)$ and 30 females $(30.30 \%)$. Out of a total of $99,87(87.9 \%)$ complications occurred in patients of CKD while $12(12.1 \%)$ occurred in patients of AKI.

A large number of complications were present in patients with CKD than AKI. The maximum complication in CKD was hypotension(17) and vascular access problem(17) followed by muscle cramps(14), chills and rigors(13) hypoglycemia (8), pre dialysis complication(8), fever(8), headache(6), itching(6), psychosis(4), restlessness(4), syncope(4), blurring of vision(3), hypoxia(2), death(2), arrhythmias(2), death(2) and hypertension(1). In patient's with AKI complications like hypertension, blurring of vision, restlessness, psychosis, cough, syncope and arrhythmias were absent. Maximum complication in AKI was chills and rigors(4) followed by muscle cramp(2), seizure(2), nausea (2), vomiting(2), fever(2), hypoxia(2), death(2), hypoglycemia(1), cardiac arrest(1) and vascular access problem(1) [Table 2]

All pre dialysis complication occurred within 5 weeks of HD. Hypotension was seen mostly in 2140 weeks and least in less than 5 weeks duration. Nausea was seen maximum in less than 5 weeks of duration of HD. Vomiting was equally common in less than 5 week and 21-40 weeks of HD. Fever was mostly common in 11-20 weeks of complication. Chills and rigors was seen equally in less than 5 and more than 40 weeks of HD. Muscle cramps were most common after 40 weeks of HD. Seizures were most common in less than 5 weeks of HD. Arrhythmias were equally common in 11-20 and 21-40 week duration of HD. Headache and cardiac arrest were maximum below 5 week category. Itching was seen maximum in 11-20 week duration of HD. Hypoxia was seen maximum in 6-10 week duration of HD. Death was noted in less than 5 week and 6-10 week duration of HD. Hypoglycemia was seen maximum in 11-20 week duration of $\mathrm{HD}$ and least in less than 5 week duration. Cough and syncope was seen maximum in above 40 week of HD. Vascular access complication was seen mostly in 21-40 duration of HD. Hypertension was seen only in above 40 week of HD. Blurring of vision, psychosis and restlessness was seen mostly in below 5 week duration of HD. 
Table 1. Correlation of multiple complications with no.of patients in a single episode of HD

\begin{tabular}{|l|l|}
\hline Number of complications & Number of patients \\
\hline 1 & 52 \\
\hline 2 & 33 \\
\hline 3 & 7 \\
\hline 4 & 6 \\
\hline 5 & 1 \\
\hline
\end{tabular}

Table 2: Distribution of complications with relation to age

\begin{tabular}{|c|c|c|c|c|c|c|c|c|}
\hline Age group & $\leq 30$ & $31-40$ & $41-50$ & $51-60$ & $61-70$ & $>70$ & Total & Percentage \\
\hline Hypotension & 0 & 2 & 1 & 6 & 4 & 5 & 18 & 18.18 \\
\hline Vascular prob. & 0 & 0 & 5 & 4 & 6 & 3 & 18 & 18.18 \\
\hline Chills and rigors & 2 & 3 & 1 & 3 & 6 & 2 & 17 & 17.17 \\
\hline Muscle cramps & 1 & 4 & 1 & 4 & 6 & 0 & 16 & 16.16 \\
\hline Pre dialysis & 0 & 2 & 2 & 4 & 2 & 1 & 11 & 11.11 \\
\hline Cough & 1 & 0 & 1 & 4 & 2 & 2 & 10 & 10.10 \\
\hline Hypoglycemia & 2 & 1 & 1 & 1 & 4 & 0 & 9 & 9.09 \\
\hline Nausea & 1 & 3 & 1 & 1 & 3 & 0 & 9 & 9.09 \\
\hline Hypoglycemia & 2 & 1 & 1 & 1 & 4 & 0 & 9 & 9.09 \\
\hline Headache & 1 & 1 & 0 & 4 & 2 & 0 & 8 & 8.08 \\
\hline Fever & 0 & 3 & 0 & 1 & 1 & 2 & 7 & 7.07 \\
\hline Itching & 1 & 0 & 1 & 2 & 2 & 0 & 6 & 6.06 \\
\hline Syncope & 0 & 0 & 0 & 0 & 4 & 0 & 4 & 4.04 \\
\hline Psychosis & 0 & 3 & 0 & 0 & 1 & 0 & 4 & 4.04 \\
\hline Restlessness & 0 & 2 & 1 & 0 & 1 & 0 & 4 & 4.04 \\
\hline $\begin{array}{l}\text { Dialysis Disequilibrium } \\
\text { Syndrome }\end{array}$ & 0 & 4 & 0 & 0 & 0 & 0 & 4 & 4.04 \\
\hline Seizures & 2 & 1 & 0 & 0 & 0 & 0 & 3 & 3.03 \\
\hline Blurring of vision & 0 & 1 & 0 & 0 & 2 & 0 & 3 & 3.03 \\
\hline Death & 0 & 0 & 0 & 2 & 0 & 1 & 3 & 3.03 \\
\hline Cardiac arrest & 0 & 0 & 0 & 2 & 0 & 1 & 3 & 3.03 \\
\hline Hypoxia & 0 & 0 & 0 & 2 & 0 & 1 & 3 & 3.03 \\
\hline Arrhythmias & 0 & 1 & 0 & 0 & 1 & 0 & 2 & 2.02 \\
\hline Hypertension & 0 & 0 & 0 & 1 & 0 & 0 & 1 & 1.01 \\
\hline
\end{tabular}




\section{DISCUSSION}

Our study was done to determine the complications occurring during and immediately after dialysis along with the variation in complications in patients suffering from CKD and AKI. We also correlated the prevalence of various complications in CKD on maintenance HD with duration of CKD and between the complications of HD and the comorbidities like DM and HTN associated with it.

Out of the total of 3000 episodes of HD complications were seen during 99 episodes of HD $(3.33 \%)$ of the total number of HD as compared to Singh LK et al1(10\%) and Abrar Ahmad et al2(8\%)showing these two studies had relatively higher number of complications.

Maximum number of complications in our study were in the age group of 61 to 70 years $(30.3 \%)$ followed by 51-60, 31-40, >70, 41-50 and finally less than 30 and out of a total of 99 episodes of HD with complications, 69 were in males i.e. around $69.69 \%$ and the rest $30(30.30 \%)$ in females. In a study by Abrar Ahmad et al2 maximum complications were in the age group of $31-40(30 \%)$ followed by 51-60, 31-40 and least in 21-30 with 52\% males and $48 \%$ females, whereas a study by Jamesen et al3showed results which were similar to those of our study\& showed that male gender was more prone to HD associated complications.

Out of the 99 episodes of HD having complications, in our study, 87(87.86\%) were in CKD patients and the rest $12(12.14 \%)$ were in AKI. In a study conducted by Collins DM et al4around $75 \%$ patients were of CKD and $25 \%$ were AKI and by Levy MB et al5 around $84 \%$ were CKD and the rest AKI.

In a study conducted by Abrar Ahmad et al2 showed that the maximum complications below the age of 30 was seizures, headache, nausea and chills. This finding was consistent with our results. Cough, itching and hypotension were mainly seen in patients above the age of 40 . This was also noted in two other studies done by Collins DM et al4 and Jamesen et al3. DDS was seen mostly in the age group of less than 40 years in our study. This was corroborated by studies done by Granord WA et al6 and Collins DM et al4. Death was a complication in our study purely in an age group of more than 50 years. In a study done by Granord WA et al6 death was seen in ages above 30, in accordance with those of ours.

In our study the maximum complication associated with AKI was chills and rigors this was seen in a study done by Nguyen Hoanetal7 which also showed the complications occurring in AKI patients were mostly seen during the first few dialysis. Our study showed that AKI patients undergoing dialysis had a greater chance of having grave complications like death, hypoxia and seizures. The study done by Helmut Schifflet al8 also showed similar results. One common feature of our study, Nguyen Hoan Phuet al8 and Helmut Schifflet al7 is that in patients with AKI complications like itching, cough, blurring of vision and psychosis were not observed.

In CKD patients, the most common complications were hypotension and vascular access complications similar to study done by Lazarus $\mathrm{JM}$ et a19. We also observed that a large number of the patients of CKD on maintenance HD had cough and itching as a major cause of concern similar with two other studies conducted by Blachley JD et al10 and Collins DM et al4. In our study DDS was $4.5 \%$ of the total complications seen in CKD patients our findings were in accordance with a study conducted by Helmut Schifflet al8.

Out of the three deaths recorded in our study during HD, two patients had both DM and HTN as co-morbities. This finding of ours was similar to that of the study conducted by Cohle SD et al11. In our study patients suffering from HTN had a larger number of complications related to AV fistula, patients having DM had a greater chance of having hypotension during HD.All our findings matched with the study done by Alan S. Go et al12. In our study the patients having HTN as co-morbidity was $54 \%$ while those having DM was $32 \%$ and the ones having both DM and HTN was $14 \%$. A study in Lancet by Meguid El Nahaset al13 showed that out of the patients 
having CKD, 45\% had HTN, 30\% had DM and $25 \%$ had both HTN and DM.

In a study done by Abrar Ahmad et al 2 around $28 \%$ of the total complications were constituted by abdominal symptoms like cramps, vomiting and pain abdomen, but in our study this constituted $9.09 \%$. In our study out of the total patients having vomiting $77.77 \%$ were males and $22.23 \%$ were females. In our study patients having hypotension $66.66 \%$ were males and $33.34 \%$ were females, in patients having arrhythmias and headache $50 \%$ were males and 50\% females, chills was seen $3 \%$ in males and $45 \%$ in females, fever was seen $60 \%$ in males and $40 \%$ in females, DDS was seen $75 \%$ in males and $25 \%$ in females, seizures was seen $30 \%$ in males and $70 \%$ in females, muscle cramps was seen $65 \%$ in males and $35 \%$ in females. Our study was in proximity with a study done by Arif Khan et al14.

In our study the maximum number of complications occurred during the first five weeks of HD.It constituted around 43(26.87\%) of the total number of complications, followed by $37(23.10 \%)$ in $21-40$ weeks, $35(21.87 \%)$ in more than 40 weeks of HD. The least number of complications were seen in 6-10 weeks of HD i.e. 20(12.5\%). A study by Daniel j. Ahearn et al15andZibari GB16 et al showed findings that were not in accordance with our study.

In our study muscle cramps formed around $16.16 \%$ of the total number of complications as compared to study done by $\mathrm{H}$ Bregman et $\mathrm{al}^{17}(14 \%)$ and Singh LK et $\mathrm{al}^{1}(20 \%)$.

In our study 6 patients $(6.06 \%)$ developed itching during HD as compared to Blachley JD et $\mathrm{al}^{10}$ $18.06 \%$ and Vandana S. Mathuret $\mathrm{al}^{18} 43 \%$.

In a study done by Chiao-Yin Sun et $\mathrm{al}^{19}$ around $31(41.03 \%)$ of the patients had hypoglycemia as compared to our study where $9(9.09 \%)$ of the patients had hypoglycemia.

\section{CONCLUSION}

The most frequent complication occurring during HD was vascular access related (18.18\%) and hypotension $(18.18 \%)$ and the least was hypertension $(1.01 \%)$.
Most common complication in case of AKI was chills and rigors while in CKD, vascular access and hypotension were the most common.

Complications were seen more frequently during the initial week of maintenance HD for CKD, less than 5 weeks of HD (26.87\%), followed by those in 21-40 weeks of $\operatorname{HD}(23.12 \%)$, more than 40 weeks(21.87\%), 11-20 weeks(15.62\%) and least in 6-12 weeks(12.5\%).

Patients having both DM and HTN had more severe and life threatening complications than patients having any one disease as comorbidity.

\section{REFERENCES}

1. Singh LKS, Devi PS, Singh Y I. Complications during Hemodialysis. The Indian Practitioner. 2007; 41:13-18.

2. Abrar Ahmad, Arif Khan. The frequency of complications of hemodialysis. Pakistan J Med. Res. 2002:41:695-699.

3. Jamesen. Weigmann TB. Uses and complications of hemodialysis. Med Clin Am 1990; 74(4): 945-60

4. Collins DM. Lamber MB. Tolerance of hemodialysis. J Am SocNephro 1993; 4(2): $148-2$

5. Levy MB. The quality of life on maintenance hemodialysis. Lancet 1988; 6: 305-9.

6. Granord WA. The psychiatrist contribution to renal unit undertaking hemodialysis. $\mathrm{Br}$ J P sychiatry 1967; 113:1701.

7. Nguyen HoanPhu, M.D., Tran TinhHien, M.D., Nguyen Thi Hoang Mai, M.D., Tran Thi Hong Chau, M.D., Ly Van Chuong, M.D., Pham PhuLoc, M.D., Christopher Winearls, D.Phil., M.B., Jeremy Farrar, M.B., D.Phil., Nicholas White, M.D., D.Sc., and Nicholas Day, B.M., B.Ch.NEngl J Med 2002; 347:895-902.

8. Helmut Schiffl, M.D., Susanne M. Lang, M.D., and Rainald Fischer, M.D.N Engl J Med 2002; 346:305-310

9. Lazarus JM. Complications in hemodialysis: an overview. Kidney Int 1980;18:783 
10. Balchey JD, Blankership DM, Menter A. Uremic Pruritis. Am Kidney Dis 1985;5:237-241

11. Cohle SD, Graham MA. Sudden death in hemodialysis. J. Forensic Sci 1985;30:16

12. Alan S. Go, M.D., Glenn M. Chertow, M.D., M.P.H., Dongjie Fan, M.S.P.H., Charles E. McCulloch, Ph.D., and Chiyuan Hsu, M.D.N Engl J Med 2004; 351:1296-1305

13. A Meguid El Nahas, FRCPa, Aminu K Bello. Chronic kidney disease: the global challenge. The Lancet. Volume 365, Issue 944, 22 January 2005, Pages 331-340

14. Arif Khan. The frequency of complications of hemodialysis. Pakistan J Med. Res. 2002:41:695-699.

15. Daniel j. Ahearn, M.D.; John f. Maher, M.D.Ann Intern Med. 1972;77(2):201204. doi:10.7326/0003-4819-77-2-201.

16. Zibari GB, Rohr MS, Landreneau MD, Bridges RM. Chronic kidney disease: the global challenge. The Lancet. Volume 365, Issue 944, 22 January 2005, Pages 331-340.

17. H Bregman, JT Daugridas. Complications during hemodialysis. Handbook of hemodialysis. $3^{\text {rd }}$ edition: Lippinkott Williams.2001:4:1243-4.

18. Vandana S. Mathur, Jill Lindberg, Michael Germain, Geoffrey Block, James Tumlin,Mark Smith, MandeepGrewal, Dawn McGuire. A Longitudinal Study of Uremic Pruritus in Hemodialysis Patients. Clin J Am SocNephrol. 2010 August; 5(8): 1410-1419.

19. Chiao-Yin Sun, Chin-Chan Lee, and MaiSzu Wu. Therapeutic Apheresis and Dialysis. Journal International Society for Apheresis. 2009.13(2):95-102. 